\title{
METRO HATLARINDAKİ RAY GERILIMINI EN 50122 STANDARDINA UYGUN OLARAK SINIRLANDIRILMADA KULLANILAN YÖNTEMLERİN KARŞILAŞTIRILMASI
}

\author{
Mehmet Taciddin AKÇAY ${ }^{1}$ \\ ${ }^{I}$ Istanbul Büyükşehir Belediyesi, Istanbul/TÜRKIYE
}

\section{$\ddot{O} z$}

$\mathrm{Bu}$ çalışmada DC beslemeli raylı sistemlerde ray toprak geriliminin devre topolojisi üzerinden analizi yapılarak bu problemin çözümü için kullanılan kontrol yöntemleri karşılaştırmalı olarak anlatılmıştır. Devre modeliyle birlikte ilgili standart anlatılarak, uygulanan yöntemlerin başarı oranı önceki durumla karşılaştırılarak hesaplanmıştır. EN 50122 standardı ilgili kısımda anlatılarak işletmenin sağlaması gereken değerler verilmiştir. Çalışma için ray geriliminin düşürülmesi için işletmede tercih edilmesi muhtemel yöntemler benzetim üzerinden grafiklerle anlatılmıştır. $\mathrm{Bu}$ yöntemlerden besleme gerilimi değiştirilerek sistemin her bir gerilim seçiminde ayrı ayrı çalıştırılması, sistemin besleme bölgesine ek bir besleme merkezi ilave edilmesi, ray iletkenine paralel bir iletken bağlanması, araç sinyalizasyon teknolojisi yardımıyla enerjinin verimli kullanılması ve VLD (gerilim limitleme cihazı) ekipmanının kullanılması yöntemleri tercih edilerek sistem çözümlenmeye çalışılmıştır. Çalışmada VLD ekipmanı çalışma algoritması verilirken yöntemlere ait elde edilen sonuçlar ve iyileştirme oranları karşılaştırmalı olarak tablo ile verilmiştir. Sonuç olarak kullanılan bu beş yöntemle sırasıyla \% 12.5 ile \% 56.2 arasında, \% 71.4, $\% 54.3$ ve \% 74.3 başarı elde edilmiştir. Son yöntemde ise ray gerilimi kısa devreden dolayı sıfır olduğu için \% 100 başarı sağlanmıştır.

Anahtar Kelimeler: Analiz, Gerilim, Kontrol, Ray, Toprak. 


\title{
COMPARISON OF THE METHODS USED IN LIMITING RAIL VOLTAGE IN METRO LINES IN ACCORDANCE WITH EN 50122 STANDARD
}

\begin{abstract}
In this study, the analysis of the rail ground voltage in DC powered rail systems over the circuit topology and the control methods used to solve this problem are explained comparatively. By explaining the relevant standard with the circuit model, the success rate of the applied methods is calculated by comparing with the previous case. The EN 50122 standard is described in the relevant section and the values that the operation must provide are given. For the study, the methods that are likely to be preferred in the enterprise to reduce the rail voltage are explained with graphics by simulation. Among these methods, operating the system separately for each voltage selection by changing the supply voltage, adding an additional feeding center to the supply area of the system, connecting a conductor parallel to the rail conductor, using the energy efficiently with the help of vehicle signaling technology and using the VLD (voltage limiting device) equipment are preferred and system has been tried to be resolved. While the VLD equipment working algorithm is given in the study, the results and improvement rates obtained from the methods are given in a comparative table. As a result, success was achieved between $\% 12.5$ and \% 56.2, \% 71.4, \% 54.3 and \% 74.3 with these five methods. In the last method, \% 100 success has been achieved since the rail voltage is zero due to short circuit.
\end{abstract}

Key Words: Analysis, Control, Ground, Rail, Voltage.

\section{Giriş}

Raylı ulaşım sistemlerinde yapılan yatırımlar dünya genelinde hız kesmeden devam etmektedir. Yeni hatların işletmeye açılmasıyla birlikte elektrifikasyon sistemi de teknolojiyle eşgüdümlü olarak kendini yenilemektedir. Elektrikli ulaşım sistemlerinde ülkemizde ve dünyada çeşitli gerilim aralıkları kullanılırken şehir içi elektrikli raylı sistemlerin önemli bir kısmında DC gerilim tercih edilmektedir. Besleme gerilimleri belirlenirken hat özellikleri, kapasite ihtiyacı, yerel şebekenin durumu gibi birtakım etmenler etkili olurken her sistem kendi içinde bazı avantajlar sağlarken bazı olumsuz durumlara da neden olabilmektedir. AC şebeke yapısına sahip ülkelerde raylı sistem araçları ihtiyacı olan enerjiyi AC beslemeli hatlarda cer transformatörü ile elde ederken DC hatlarda bu durum farklı olmaktadır. DC beslemeli hatlarda AC gerilim DC gerilime 
dönüştürülerek ihtiyaç olan enerji elde edilmektedir. DC gerilim, şehir içi hatlarda elektrifikasyon sisteminin tasarımı için optimal koşulları sağlamakla birlikte istenmeyen bazı durumların da ortaya çıkmasına neden olmaktadır. AC şebekeye enerji dönüşümü için ek olarak bağlanan ilave ekipmanlarla işletme ve bakım maliyetleri artarken sistemde bulunan redresör negatif ucunun bağlantı noktasının topraktan izole olmasının sonucunda raylarda gerilim meydana gelmektedir [1 5]. Şekil 1 ile ray geriliminin oluşumuna ait eşdeğer bağlantı devre elemanları kullanılarak ifade edilmektedir.

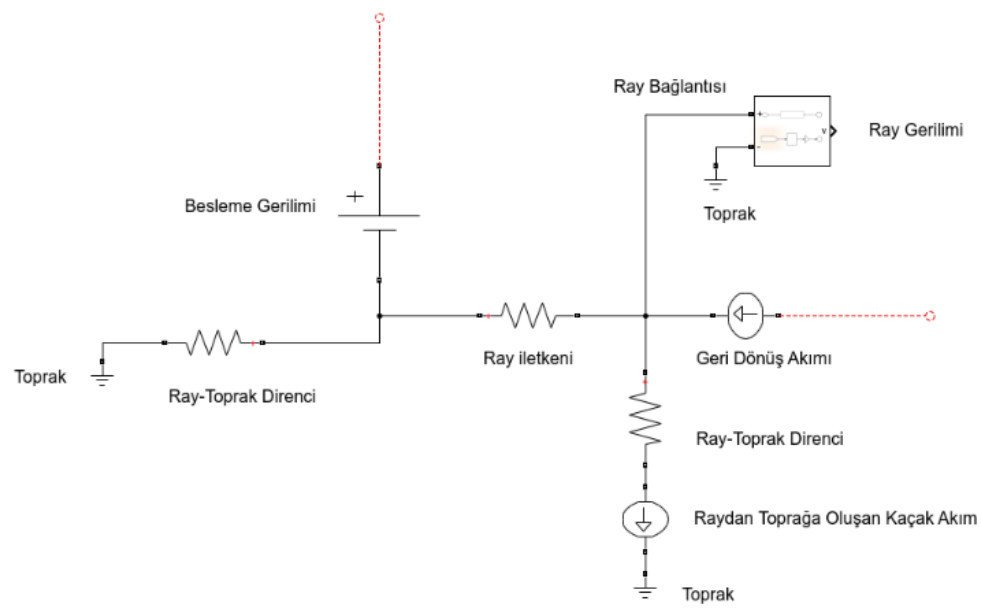

Şekil 1. Ray Gerilimi ve Kaçak Akımın Oluşumu

Besleme gerilimi ile aracın ihtiyacı olan akım elde edilirken araçtan kaynağa doğru dönen akım raylar vasıtasıyla sağlanmaktadır. DC beslemeli hatlarda raylar genellikle cer akımının geri dönüş iletkeni olarak kullanılmaktadır [1]. Bu tercih ekonomik nedenlerden kaynaklanmakta olup bu şekilde akımın taşınması için özel bir montaj gerekliliği ortadan kaldırılmaktadır [2]. Mükemmel yalıtım mümkün olmadığı ve rayın sonlu bir dirence sahip olmasından dolayı dönüş akımı toprağa sızar ve en az dirençli yolu tercih ederek besleme merkezine geri döner [3]. Geri dönüş iletkeni olarak rayların kullanılmasından ötürü raylarda gerilim meydana gelmektedir. Raylı sistemlerde oluşan ray gerilimin, kaçak akımların kontrol edilmesi ve EN 50122 standardının sağlanmasının gerekliliği bu çalışmasının gerekçesini oluşturmuştur. Bu gerilim literatürde dokunma gerilimi diye isimlendirilmiştir. Araç hareketleri ile raylarda ortaya çıkan kaçak akımlar cer besleme 
Akçay/Kırklareli University Journal of Engineering and Science 7-2 (2021) 272-291

Geliş Tarihi:21.01.2021

merkezlerine yakın bir noktada raya geri dönmektedir [4]. Oluşan akım raylardan kaynağa doğru dönerken ray ile toprak farklı potansiyelde olduğu için raydan toprağa doğru kaçak akımlar ortaya çıkmaktadır. Bu akımlar raylarda ve demiryolu yakınındaki gömülü metalik yapılarda korozyona neden olmaktadır [5]. Oluşan kaçak akımları minimize etmek için kaçak akım kontrol sistemleri uygulanmaktadır [6]. Kaçak akımları azaltma yöntemleri genel olarak elektriksel direncin azaltılması ve izolasyon direncinin arttırılması olarak iki temel prensibe dayanmaktadır [7]. Katodik koruma yine kaçak akımların yarattığı korozyonu azaltmak için kullanılan bir yöntemdir [8]. Oluşan korozyonun hızı dış boyu hattının yüzeyi Kaçak akımlar ve ray gerilimleri güncel metro sistemlerinde çözümlemesi zor konulardır [9]. DC beslemeli hatlarda rayların topraktan izolasyonunun en iyi seviyede olması beklenirken bu duruma ait kriterler EN 50122 standardı ile ifade edilmiştir. EN 50162'de ise kaçak akımlar sonucu oluşan tehlikelerin derecelendirilmesine ait bazı yöntemler anlatılmaktadır [10]. Bu standart ile sistem için olması gereken minimum koşullar belirtilirken standardın üstünde elde edilen veriler için sistem daha yüksek performans sağlamaktadır. Yüksek ray gerilimi insan hayatıyla ilgili önemli derecede tehlikeli durumlar ortaya çıkarabilmektedir [11]. Yoğun işletme altında araç hareketiyle birlikte aracın ihtiyaç duyduğu akım bin amperler seviyesinde artarken rayın miliohm'lar seviyesindeki elektriksel direnci sonucu raylarda (60-100 V) gerilim düşümü oluşmaktadır [12]. EN 50122'e göre ray-toprak elektriksel direnci $2 \Omega \mathrm{km}$ 'ye kadar izin verilirken tasarım için önerilen değer ise $100 \Omega \mathrm{km}$ mertebesindedir [13]. Akım yoğunluğu dış ortamın ve yüzeyin elektriksel iletkenliğine bağlıdır [14]. Bu çalışmada ray gerilimi ve kaçak akımların azaltılması için uygulanması önerilen bazı yöntemler verilerek benzetim üzerinden analiziyle performans durumlarının karşılaştırılmalı olarak anlatılması amaçlanmıştır

\section{Materyal ve Metot}

$\mathrm{Bu}$ çalışmada DC beslemeli bir raylı sistem hattında elektrifikasyon sistemine ait eşdeğer devre modellenerek Matlab/Simulink ortamında benzetimi yapılmıştır. Benzetim için alt sistemlere ait veriler kullanılmıştır. Oluşturulan model ile ray gerilimini ve kaçak akımı azaltmak için alınan tedbirler bu devre üzerinden çözümlenmiştir. 2.1'de anlatılan devre topolojisi üzerinden benzetim modeli oluşturularak farklı yöntemler üzerinden sistem test edilmiştir. I. yöntemde Besleme 
gerilimi değiştirilerek sistem her bir gerilim seçimi için ayrı ayrı çalıştırılırken II. yöntemde sistemin besleme alanına ek bir besleme merkezi konumlandırılarak sistem bu şekilde çalıştırılmıştır. III. yöntemde ise ray iletkenine paralel bir iletken bağlanarak devre tamamlanmıştır. Burada raylarda bulunan elektriksel direncin düşürülmesi hedeflenmiştir. IV. yöntemde ise enerji optimizasyonu seçeneğiyle araçların birbiriyle haberleşme altyapısı ile bilgi alışverişinde bulunduğu durum gözönüne alınarak araçların aynı anda pik değerlerde akım çekmesinin önüne geçilerek besleme merkezlerinin daha az faaliyet göstermesi sağlanmıştır. Son yöntemde ise VLD ekipmanı ile ray gerilimi değerine bağlı olarak ray toprak arasını kısa devre eden bir cihaz uygulanmıştır.

\subsection{Devre Topolojisi}

DC beslemeli bir raylı sistem hattının işletme halinde olduğu iki besleme merkezi arası bölgenin temsil edildiği eşdeğer devre şekil 2 ile gösterilmiştir. Bu model ile 2.5 km'lik bir bölgede 4 adet aracın işletme altında olduğu durum ifade edilmiştir.

Vh1 ile Vh2 karşılıklı DC cer besleme merkezlerine ait kaynak gerilimini ifade etmektedir. Bu iki nokta arasındaki numerik aralıklara yerleştirilen dirençlerden her biri 0.5 km'lik mesafelere eşdeğer hat dirençlerini simgelemektedir. (1) denklemi ile n. araca ait hattan çekilen akım In hesaplanırken $\mathrm{r}$ ray gerilimine ait direnci simgelemektedir. $\mathrm{t}$ ray-toprak direncini ifade ederken $\mathrm{k}$ ile katener (3.ray) hattına ait direnç gösterilmiştir. V ray gerilimini göstermekte olup Vh1 kaynak geriliminin eksi ucuna bağlı olan kısım 0 noktasını göstermektedir. rn. direnç ile $\mathrm{rn}+1$. direnç arasındaki kısım n. noktayı temsil etmektedir.

$\left[\begin{array}{ll}\frac{1}{r_{n}} & \frac{1}{r_{n+1}}\end{array}\right]\left[\begin{array}{c}V_{n-1} \\ V_{n+1}\end{array}\right]=\left[\frac{1}{r_{n}}+\frac{1}{r_{n+1}}+\frac{1}{t_{n+1}} \quad 0\right]\left[\begin{array}{c}V_{n} \\ 0\end{array}\right]-\left[I_{n}\right]$

(1) nolu denklem bazı matris işlemleri yapılarak geliştirildiğinde ise (2) nolu eşitlik elde edilerek n. noktaya ait ray gerilimleri hesaplanmaktadır.

$$
\left[\begin{array}{l}
V_{n} \\
0
\end{array}\right]=\left[\frac{1}{r_{n}}+\frac{1}{r_{n+1}}+\frac{1}{t_{n+1}} \quad 0\right]^{-1}\left[\left[\begin{array}{ll}
\frac{1}{r_{n}} & \frac{1}{r_{n+1}}
\end{array}\right]\left[\begin{array}{c}
V_{n-1} \\
V_{n+1}
\end{array}\right]+\left[I_{n}\right]\right]
$$


(3) ile n. araca ait güç denklemi verilirken $V_{-}$arac araç üzerindeki gerilimi ifade ederken, Pn n. araca ait gücü göstermektedir.

$P_{n}=V_{\text {arac }} I_{n}$

(4) eşitliğinde ise aracın çektiği güç araca etkiyen cer kuvveti (F) ve aracın hızı (v) kullanılarak elde edilen eşitlik verilmektedir.

$P_{n}=F v$

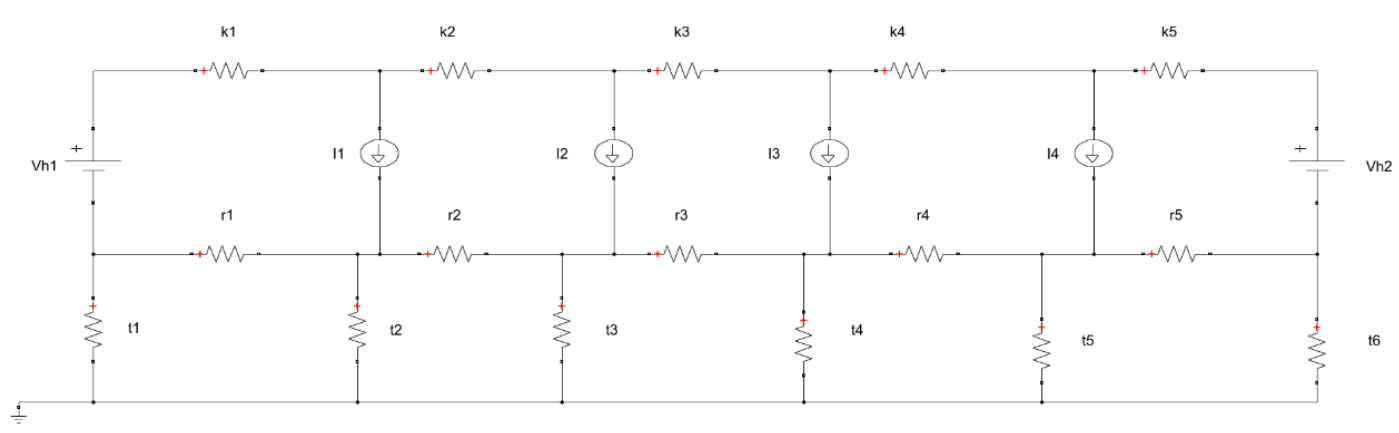

Şekil 2. İşletme Altında DC Demiryoluna ait Eşdeğer Devre

Cer kuvveti hız eğrisi araca ait karakteristik bir özellik olup araç üreticisinin konfigürasyonuna göre değişiklik gösterebilmektedir. İşletme altında olan araç sayısı ise (5) denklemi ile elde edilmektedir. A araç sayısı iken $\Delta$ t iki nokta arasında gerçekleşen seyir süresini ifade etmektedir. h ise raylı sistem işletmesinde sinyalizasyon sistemi için çok önemli bir parametre olan sefer sıklı̆̆ süresini göstermektedir [15].

$A=\Delta \mathrm{t} / h$

DC demiryollarında sistem güç elektroniği dönüştürücüleri, ray, elektrik motoru, kontrol sistemi ve mekanik sistemleri içeren kompleks bir yapıya sahiptir [16]. 
Araştırma

DOI: $10.34186 /$ klujes. 1051445
Akçay/Kırklareli University Journal of Engineering and Science 7-2 (2021) 272-291

Geliş Tarihi:21.01.2021

\subsection{Ray Gerilimi}

Ray iletkeni DC hatlarda hem geri dönüş iletkeni hem de araç hareketlerinin kontrolü için sinyalizasyon devrelerinin parçası olarak kullanılmaktadır [17]. Eksi uç olarak kullanılan ray hattı ile toprak iletkeni arasında meydana gelen gerilim ray gerilimi olarak ifade edilmektedir. $\mathrm{Bu}$ gerilim şehir içi hatlarda yolcu emniyeti ve işletme tarafından bakım dönemlerinde hat çalışmaları için tehlike unsuru olarak görüldüğü için işletme için gereken tedbirler alınmaktadır. Şekil 3 ile ray gerilimine ait şematik verilmektedir.

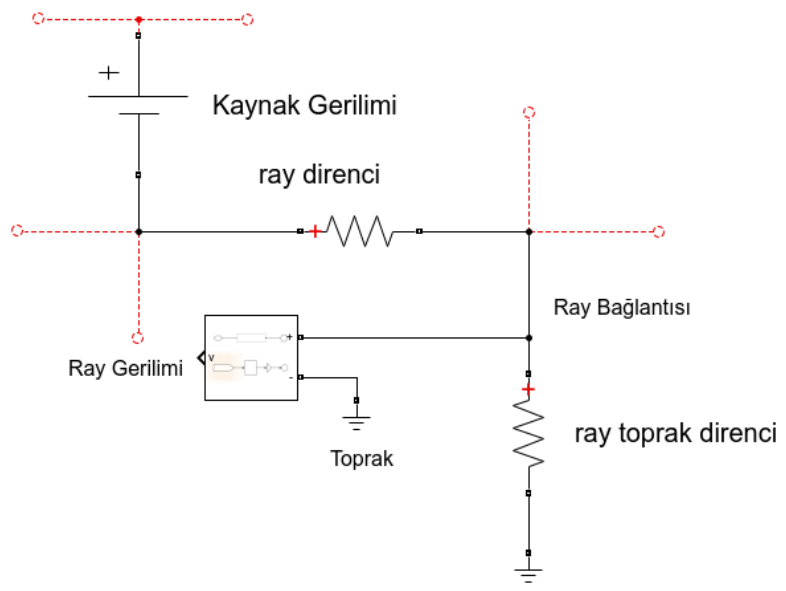

Şekil 3. Ray Gerilimi

(6) ve (7) nolu eşitlikler ile ray gerilimi ve ray akımına ait denklemler verilmekte olup burada $\mathrm{V}(\mathrm{x})$ ve i(x) gerilim ve akımı ifade etmektedir. Ray iletkenine ait karakteristik direnç R0 ile gösterilirken $\mathrm{C} 1$ ve $\mathrm{C} 2$ ilgili katsayıları göstermektedir. RG kaçak iletkenlik olurken $\mathrm{R}$ ise ray direnci olarak ifade edilmiştir. $\gamma$ sembolü ise propogasyon sabitini belirtmektedir.

$V_{(x)}=-R_{0}\left(C_{1} e^{\gamma x}+C_{2} e^{-\gamma x}\right)$

$i_{(x)}=C_{1} e^{\gamma x}+C_{2} e^{-\gamma x}$ 
Oluşan ray gerilimi hatta bulunan unsurlar için temas riskini bulunduğundan dolayı bu gerilim ayrıca dokunma gerilimi olarak tanımlanarak alınacak tedbirler bu doğrultu özelinde de değerlendirilmektedir.

\subsection{Kaçak Akımlar}

İşletme altında raylı sistem araçlarının hareketiyle oluşan ray gerilimi neticesinde oluşan akım güzergahın jeolojik yapısına ve ray izolasyon sisteminin özelliklerine bağlı olarak ortaya çıkan raytoprak direncinin üzerinden toprağa akmaktadır. Bu durum literature kaçak akım olarak girmiş olup ray altında bulunan ekipmanların ve alt sistemlerin performansına olumsuz etkiler yol açmaktadır. Kaçak akımın değerini azaltmak için ray ile toprak arasındaki izolasyon seviyesinin sonsuz derecede olması istenilsede pratikte hat koşullarının zorluğundan dolayı EN 50122 standardının sağlanması kabul kriteri sayılmaktadır.

(8) ve (9) nolu eşitlikler ile tren hareketleri geçişinden sonra hatta oluşan korozyan yükleri hesaplanmaktadır. $\mathrm{CCC}_{(\mathrm{x})}$ toplam kümülatif korozyon yükünü belirtirken, $\mathrm{i}_{\text {korozyon korozyon }}$ akımını $\mathrm{C}_{\text {korozyon }}$ ise korozyon yüklenmesini simgelemektedir.

$$
\begin{aligned}
& \operatorname{CCC}_{(x)}=\iint i_{\text {korozyon }}(x, t) d t \\
& d t=\int_{T} C_{\text {korozyon }}(x) d t
\end{aligned}
$$

Kümülatif korozyon yükü hatta meydana gelen korozyon yüklerinin toplamından oluşmaktadır. Korozyon yükü hattın ömründe korozif etkinin derecesini gösteren önemli bir etkeni tanımlamaktadır. Ray gerilimi sonrasında oluşan kaçak akımlar ana besleme sisteminden çıkıp çıktığı kaynağa geri dönmemesi açısından kayıp akım olarak değerlendirildiği için elektrifikasyon sisteminin veriminin de düşmesine neden olmaktadır. Bu durumdan ötürü kaçak akım hem sistem emniyet hem performans kriterleri açısından minimize edilmesi gereken bir değerdir. 


\subsection{EN 50122 Dokunma Gerilimi Limitleri}

Ray gerilimi hatta bulunan unsurlara yakınlığından dolayı dokunma gerilimi standartlarına uyumluluk esaslarını gerektirmektedir. Bu konuyla ile ilgili olarak EN 50122 standardı uygulanmakta olup tasarım yapılırken ray-toprak gerilimi araç hareketleri ve elektrifikasyon sistemini kapsayan detaylı analiz çalışmaları ile incelenmektedir. Bu doküman literatüre cer gücü analizi olarak girmiş olup ray gerilimi analizi bu çalışmanın bir kolunu oluşturmaktadır. Tablo 1 ile EN 50122'ye ait değerler verilmektedir.

Tablo 1. Dokunma gerilimine ait standart [EN 50122]

\begin{tabular}{|c|c|c|}
\hline $\mathbf{t}(\mathbf{s})$ & Ute max (V)uzun süreli & Ute max (V) kisa süreli \\
\hline$>300$ & 120 & - \\
\hline 300 & 150 & - \\
\hline 1 & 160 & - \\
\hline 0,9 & 165 & - \\
\hline 0,8 & 170 & - \\
\hline 0,7 & 175 & 350 \\
\hline$<0,7$ & - & 360 \\
\hline 0,6 & - & 385 \\
\hline 0,5 & - & 420 \\
\hline 0,4 & - & 460 \\
\hline 0,3 & - & 520 \\
\hline 0,2 & - & 625 \\
\hline 0,1 & - & 735 \\
\hline 0,05 & - & 870 \\
\hline 0,02 & - & \\
\hline t : süre & - & \\
Ute max: izin verilen temas gerilimi &
\end{tabular}

Bu standarda göre ray geriliminin 5 dakikadan uzun süre boyunca $120 \mathrm{~V}$ sinır değerinin üzerinde olmaması gerekmektedir. Bu değer 1 saniye ile 300 saniye arasındaki durumlar için $150 \mathrm{~V}$ olarak belirlenmiştir. Bu değer 0.6 saniyeden büyük 0.7 saniyeden küçük olarak gerçekleşen durumlar için 360 V'u geçmemelidir. Tablodan görüldüğü üzere dokunma gerilimi kısa süreler için daha yüksek rakamlara ulaşırken uzun süreler için daha az olmaktadır. Ray gerilimi analiz edilirken oluşan gerilimin bu süreler içinde bu limit değerlerin altında kalıp kalmadığı kontrol edilirken limit dışı durumlar için ilave tedbirlerin alınması gerekmektedir. 


\section{Bulgular}

$\mathrm{Bu}$ çalışmada DC beslemeli bir raylı sistem hattının elektriksel olarak modellemesi yapılarak ray gerilimi analizi yapılmıştır. Benzetim için gerçek hat verilerine ait özelliklerden yararlanılmıştır. Benzetim için farklı besleme gerilimlerinin tercih edilmesi, ek cer merkezinin sisteme ilave edilmesi, ray iletkenine parallel iletken bağlanması, araç trafiğinde enerji optimizasyonunun kullanılması, gerilim limitleme cihazlarının kullanılması gibi yöntemler uygulanarak ray geriliminin değişimi gözlemlenmiştir.

\subsection{DC İletim Hattı Besleme Geriliminin Değiştirilmesi}

Benzetim için EN 50163 standardında bulunan demiryollarında cer besleme gerilimleri seçilerek sistem test edilmiştir. Diğer tüm koşullar aynı bırakılarak ray geriliminin ve katener (3.ray) geriliminin değişimi izlenmiştir. Şekil 4'de bu duruma ait grafik gösterilmektedir.

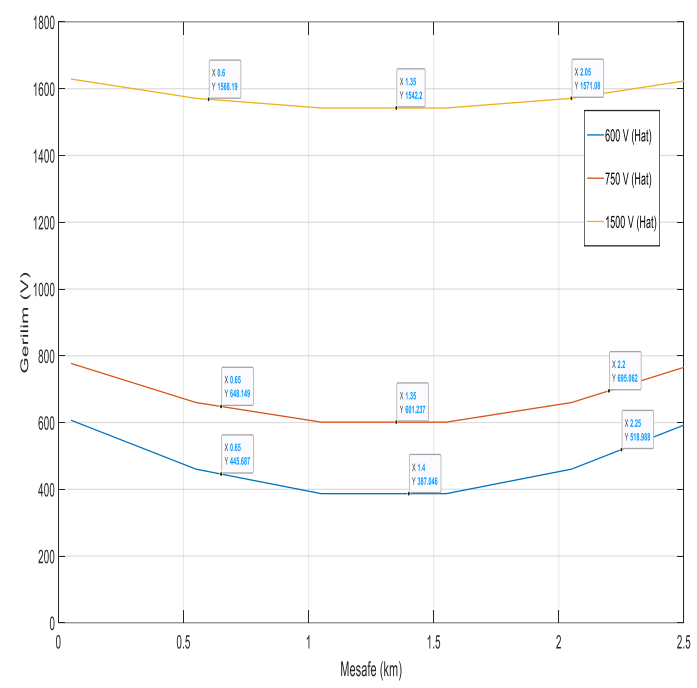

(a) İletim Hattı Gerilimi

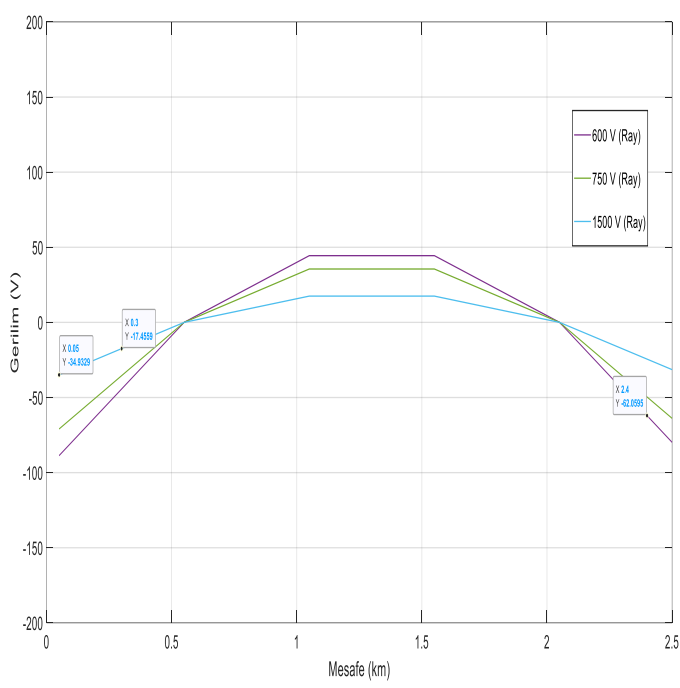

(b) Ray Gerilimi

Şekil 4. Farklı DC Gerilim Seviyelerinde Ray ve İletim Hattı Geriliminin Değişimi

Şekil 4 (a)'da görüldüğü üzere iletim hattı gerilimleri sarı, turuncu ve mavi renk ile gösterilmiş olup sırasıyla bu renkler 1500,750 ve $600 \mathrm{~V}$ besleme gerilimine karşıllk gelmektedir. Şekil 4 (b)'de Ray geriliminde ise bu gerilim seçimleri mavi, yeşil ve mor renk ile gösterilmiştir. Sisteme 
Araştırma

DOI: 10.34186/klujes. 1051445
Akçay/Kırklareli University Journal of Engineering and Science 7-2 (2021) 272-291

Geliş Tarihi:21.01.2021

$600 \mathrm{~V}, 750 \mathrm{~V}$ ve $1500 \mathrm{~V}$ besleme gerilimleri uygulanarak değişim incelenmiştir. Ray gerilimin en yüksek değeri aldığı gerilim seviyesi $600 \mathrm{~V}$ kaynak gerilimi olurken en düşük değeri aldığı kaynak gerilimi $1500 \mathrm{~V}$ olmuştur. $750 \mathrm{~V}$ seçiminde ise bu iki gerilim seviyesinin arasında gerçekleşen değerler gözlemlenmiştir. $600 \mathrm{~V}$ seviyesinde en yüksek (mutlak değer) ray gerilimi $80 \mathrm{~V}$ civarında gerçekleşirken $1500 \mathrm{~V}$ seviyesinde bu değer $35 \mathrm{~V}$ olmuştur. $750 \mathrm{~V}$ seçiminde ise bu değer $70 \mathrm{~V}$ olmuştur.

\subsection{Sisteme Ek Cer Merkezinin İlave Edilmesi}

Bu durumda aynı hat gerilimi ve diğer hat özellikleri sabit tutularak iki cer besleme noktası arasına ilave cer besleme merkezi ilave edilmesi durumundaki değişim incelenmiştir. DC Raylı sistem işletmelerinde yaygın olarak $1500 \mathrm{~V}$ DC kullanıldığı için bu gerilim durumu analiz edilmiştir. Değişimle ilgili grafik şekil 5'te gösterilmiştir.

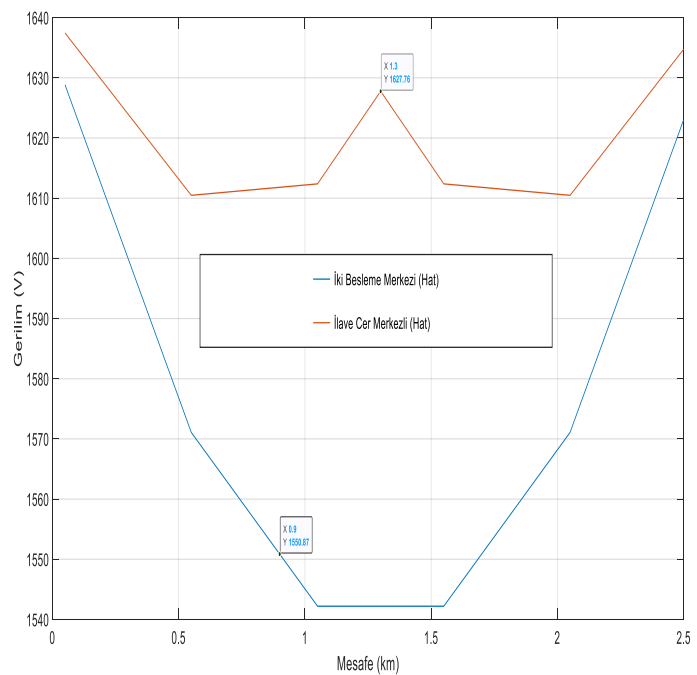

(a) İletim Hattı Gerilimi

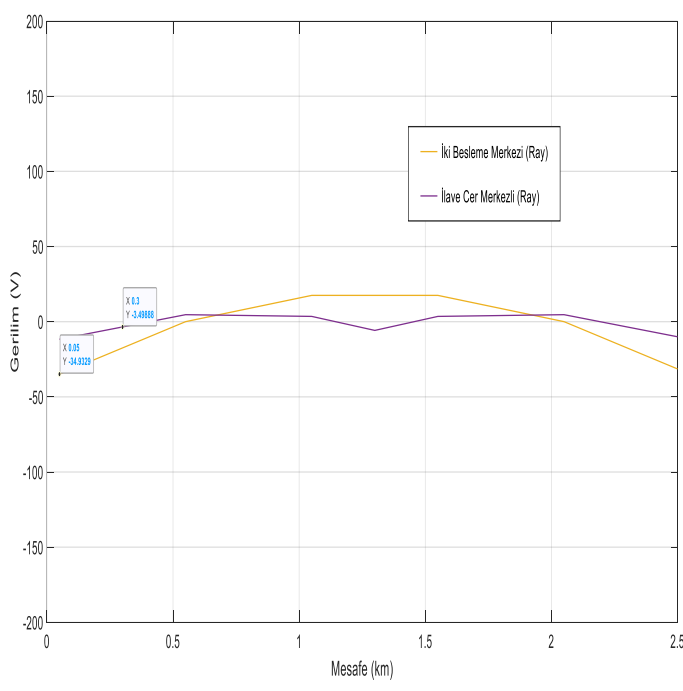

(b) Ray Gerilimi

Şekil 5. İlave Cer Merkezi Eklenmesi Durumuna ait Grafik

Şekil 5 (a) ile mavi renk ile iki besleme merkezi olması durumu gösterilirken turuncu renk ile bir cer merkezinin sisteme ilave edilmesi durumundaki değişim gösterilmiştir. Şekil 5 (b)'de ise bu durumun gösterimi için sarı ve mor renkleri seçilmiştir. İlave cer merkezi eklenmeden önce $35 \mathrm{~V}$ 
seviyelerinde gerçekleşen en yüksek ray gerilimi cer merkeziyle birlikte $10 \mathrm{~V}$ seviyelerinde gözlemlenmiştir. İlave cer merkeziyle birlikte hatta gerçekleşen gerilim düşümü azalarak hat gerilimi daha yüksek mertebelere ulaşırken ray gerilimi daha düşük mertebelerde gerçekleşmiştir. $\mathrm{Bu}$ yöntem işletmeye alınan hatlarda araç sayısı arttırılınca yüksek gerilim düşümünün ve cer merkezlerine düşen akım yükünün azaltılması yönünden uygulanmaktadır. Bu çözüm bu sayılanlara ek olarak ray geriliminin düşürülmesinde de kullanılmaktadır.

\subsection{Ray İletkenine paralel iletken bağlanması}

$\mathrm{Bu}$ durumda ray iletkenine paralel bir iletken bağlanarak eşdeğer direncin düşürülmesi hedeflenmektedir. Pratikte bu yöntem 250 metrede bir raylar arası bağlantı yapılarak uygulanırken bu çalışmada hat boyunca bir paralel iletkenin bağlanması durumu incelenmiştir. Direncin düşmesiyle ray üzerinde oluşan gerilim düşümü azalarak ray üzerinden geçen akım limitlenmektedir. Bu yönteme ait sonuçlar şekil 6'da gösterilmektedir.

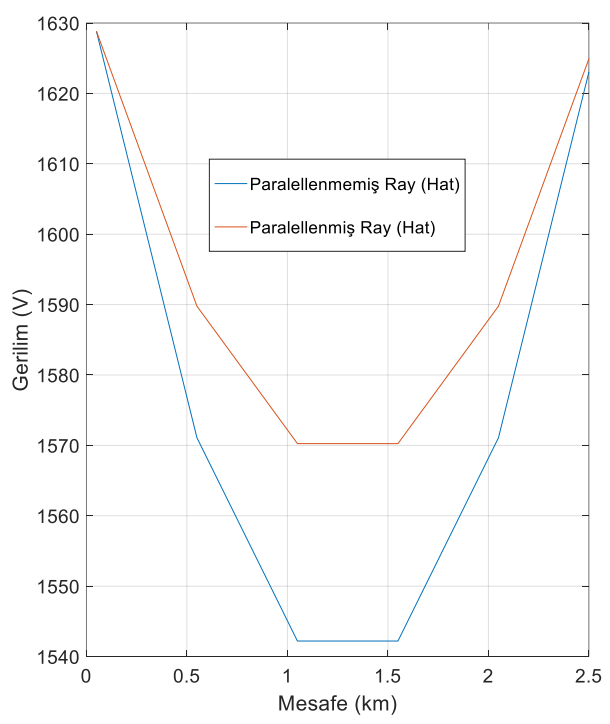

(a) İletim Hattı Gerilimi

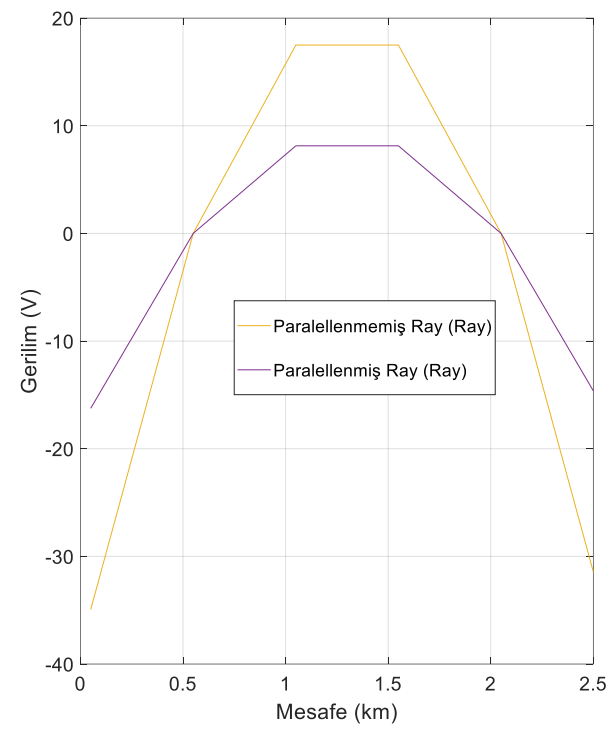

(b) Ray Gerilimi

Şekil 6. Ray İletkenlerinin Paralellenmesi ile Oluşan Sonuçlar

Şekil 6 (a) ile mavi renk ile rayların paralellenmediği duruma ait hat gerilimi sonuçları gösterilirken turuncu renk ile rayların paralellenmediği duruma ait gerilim sonuçları gösterilmiştir. Şekil 6 (b)'de 
ise bu durum için sarı ve mor renkleri seçilmiştir. Raya bağlanan paralel iletkenin direnci 0.02 $\mathrm{ohm} / \mathrm{km}$ seçilmiş olup hat boyunca raylara paralelleme işlemi yapılmıştır. Paralel ray bağlantıları yapılmadan önce ray gerilimi $35 \mathrm{~V}$ seviyelerinde görülürken paralelleme işleminin ardından bu değer $16 \mathrm{~V}$ seviyelerine kadar indirilmiştir. Bu yöntemle ray geriliminin yanısıra iletim hattı geriliminde de iyileşme sağlanarak hat geriliminin daha yüksek mertebelerde gerçekleşmesi sağlanmıştır. Paralellenmeden önce en düşük hat gerilimi 1570 V olarak kayıt edilirken paralelleme ile bu değer $1542 \mathrm{~V}$ civarına düşürülmüştür.

\section{4. İşletme Araç Trafiği Yönetiminde Enerji Optimizasyonu}

$\mathrm{Bu}$ kısımda işletme halinde olan araçların haberleşme sistemi arayıcılı̆̆ıyla bir yazılım alt yapısıyla birlikte enerji optimizasyonu sağlanarak sefer sıklığı hedefinden sapmadan işletilmesi amaçlanmaktadır. $\mathrm{Bu}$ şekilde araçların maksimum güç tüketimi trendlerinin çakışması engellenerek hattan çekilen akımın minimize edilmesi sağlanmaktadır. Bu çalışmaya ait grafik şekil 7 ile gösterilmektedir. Raylı sistemlerde enerji tasarrufu enerji fiyatındaki dalgalanmalardan dolayı çok önemli bir konudur [18].

Şekil 7 (a) ile mavi renk ile normal duruma ait hat gerilimi sonuçları gösterilirken turuncu renk ile enerji optimizasyonu uygulandığındaki duruma ait gerilim sonuçları gösterilmiştir. Şekil 7 (b)'de ise bu durum için sarı ve mor renkleri tercih edilmiştir. Grafikte görüldüğü üzere enerji optimizasyonu ile ray geriliminde ve hat geriliminde daha verimli eğriler elde edilmiştir. Enerji optimizasyonu ile araçların manevra hareketleri kontrol edilerek maksimum güç tüketim eğrilerinin çakışması engellenmiştir. Bu durumda hattan çekilen akım ve hat üzerinde oluşan gerilimde azalma meydana gelmiştir. Ray geriliminin en yüksek değeri normal durumda $35 \mathrm{~V}$ olarak kayıt edilmişken enerji optimizasyonu ile bu değer 10 V'lara kadar düşürülmüştür. Hat geriliminde ise $56 \mathrm{~V}$ civarında iyileşme sağlanmıştır. 
Araştırma

DOI: 10.34186/klujes.1051445

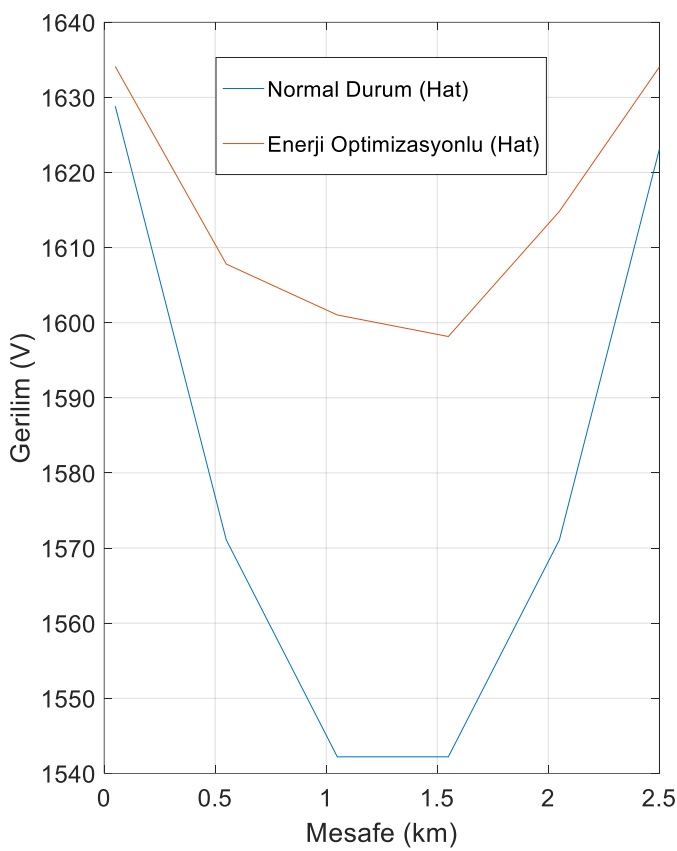

(a) İletim Hattı Gerilimi
Akçay/Kırklareli University Journal of Engineering and Science 7-2 (2021) 272-291

Geliş Tarihi:21.01.2021

Kabul Tarihi:30.06.2021

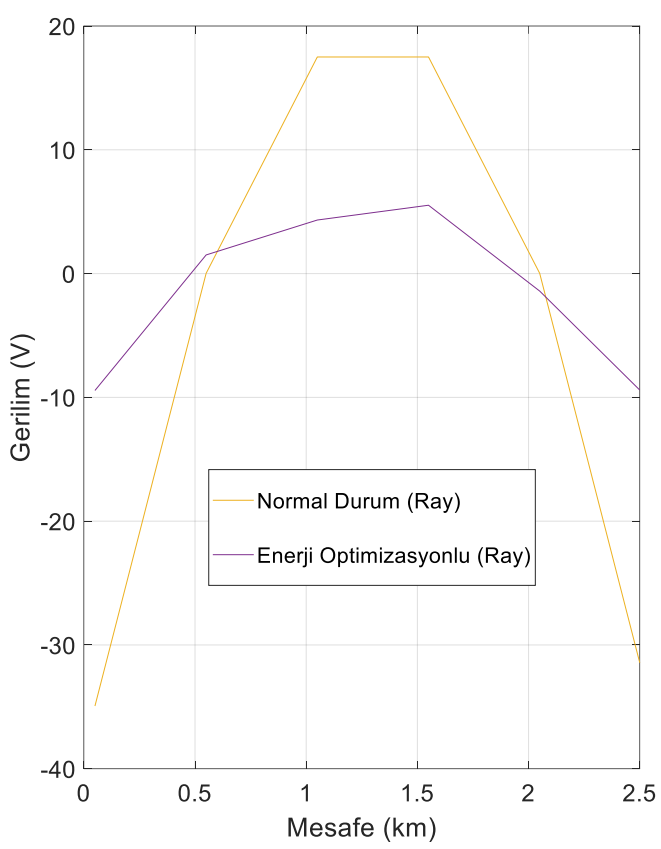

(b) Ray Gerilimi

Şekil 7. Enerji Optimizasyonlu Durumda Ortaya Çıkan Durum

\subsection{Gerilim Sınırlandırılması için Ek Cihazların Kullanılması}

Ray gerilimlerini azaltmanın bir diğer yöntemi ise gerilim sınırlandıran ilave cihazların (VLD) raya bağlanmasıdır. Bu yöntemde ray gerilimi belirli aralıklarla ölçülerek EN 50122 standardının sağlanması kontrol edilmektedir. Ray gerilimi limit dışı değerler aldığında sistem topraklanarak ray gerilimi azaltılmaktadır. Şekil 8 ile VLD cihazına ait elektriksel model gösterilmektedir.

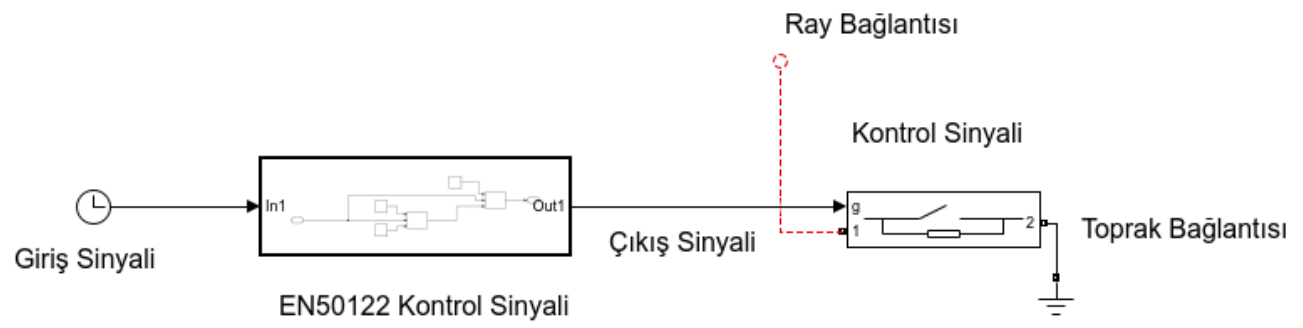

Şekil 8. VLD Cihazının Elektriksel Modeli 
Ray gerilimi limit içi değerlere ulaştığında ise sistemin toprak bağlantısı kaldırılarak nominal durumdaki işletme koşullarına devam edilmektedir.

\subsubsection{VLD Algoritması}

VLD cihazı ray gerilimini ölçerken bazı adımlar gerçekleşirken sisteme ait çalışma şartlarının standart dışına çıkmaması sağlanmaktadır. Bu adımlara ait çalışma algoritması şekil 9 ile gösterilmektedir.

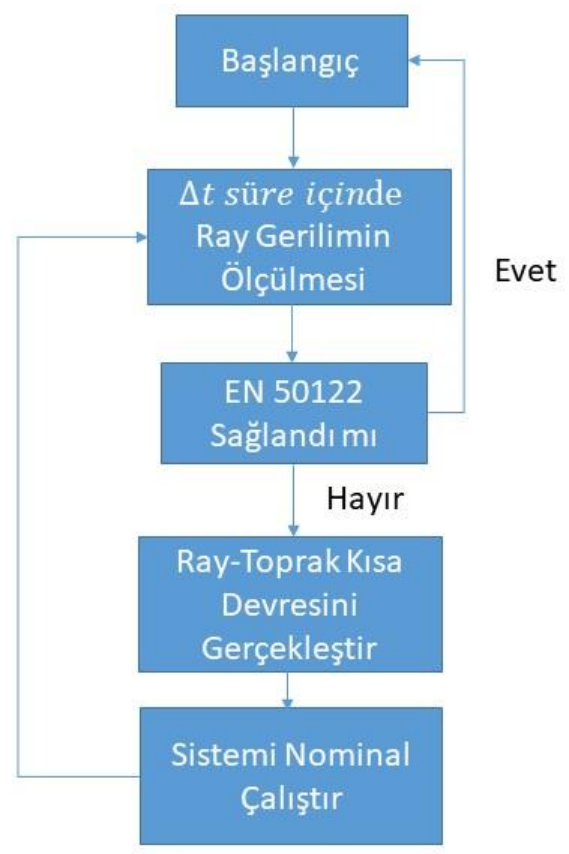

Şekil 9. VLD Çalışma Algoritması

Sistem belirli zaman aralıkların ray toprak potansiyel farkını ölçerek EN 50122 standardına uyum kriterlerine ait denetleme sağlarken limit dışı durumlarda toprakla kısa devre gerçekleştirmektedir. Kısa devre durumunun ardından sistem nominal koşullara dönerken VLD cihazı sahadan tekrar ölçüm almaya devam etmektedir. Bu durum standartta belirtilen koşulların sağlanmasında süreklilik elde edilene kadar devam ettirilmektedir. Bu adımlarla ray gerilimi kontrol altına alınmaktadır. 
Araştırma

DOI: $10.34186 /$ klujes. 1051445
Akçay/Kırklareli University Journal of Engineering and Science 7-2 (2021) 272-291

Geliş Tarihi:21.01.2021

\section{Tartışma ve Bulgular}

Ray geriliminin kontrol edilmesi için uygulanan yöntemlerin sonuçlarına ait özet durum tablo 2 ile gösterilmiştir. Yöntemler uygulanmadan ve uygulandıktan sonra ortaya çıkan durum ifade edilerek karşılaştırma yapılmıştır.

Tablo 2. Uygulanan yöntemlere ait özet durum

\begin{tabular}{|l|c|c|c|}
\hline \multicolumn{1}{|c|}{ Uygulanan Yöntem } & $\begin{array}{c}\text { Yöntem Öncesi } \\
\text { Ray Gerilimi } \\
(\mathbf{V})\end{array}$ & $\begin{array}{c}\text { Yöntem } \\
\text { Sonrası Ray } \\
\text { Gerilimi (V) }\end{array}$ & $\begin{array}{c}\text { İyileştirme } \\
\text { Oranları } \\
(\%)\end{array}$ \\
\hline $\begin{array}{l}\text { DC İletim Hattı } \\
\text { Besleme Geriliminin } \\
\text { Değiştirilmesi }\end{array}$ & $80 \mathrm{~V}$ & $70 \mathrm{~V}-35 \mathrm{~V}$ & $12.5-56.2$ \\
\hline $\begin{array}{l}\text { Sisteme Ek Cer } \\
\text { Merkezinin İlave } \\
\text { Edilmesi }\end{array}$ & $35 \mathrm{~V}$ & $10 \mathrm{~V}$ & 71.4 \\
\hline $\begin{array}{l}\text { Ray İletkenine paralel } \\
\text { iletken bağlanması }\end{array}$ & $35 \mathrm{~V}$ & $16 \mathrm{~V}$ & 54.3 \\
\hline $\begin{array}{l}\text { İşletme Araç Trafiği } \\
\text { Yönetiminde Enerji } \\
\text { Optimizasyonu }\end{array}$ & $35 \mathrm{~V}$ & $9 \mathrm{~V}$ & 74.3 \\
\hline $\begin{array}{l}\text { Gerilim Kontrolü için } \\
\text { Ek Cihazların } \\
\text { Kullanılması }\end{array}$ & $35 \mathrm{~V}$ & 0 & 100 \\
\hline
\end{tabular}

Uygulanan kontrol yöntemleriyle ilgili olarak performans değerlendirmesi yapıldığında tablodan anlaşıldığı üzere en iyi yöntem VLD cihazının sisteme bağlanmasıyla elde edilmiştir. Sonrasında bu yöntemi sırasıyla; işletme araç trafiği yönetiminde enerji optimizasyonu, sisteme ek cer merkezinin ilave edilmesi ve DC iletim hattı besleme geriliminin değiştirilmesi izlemektedir. Performans bakımınından en düşük sonuç ise ray iletkenine paralel iletken bağlanması yöntemiye sağlanmıştır. VLD yönteminin gerilim iyileştirme oranı sistemin çalışma mantığından dolayı \% 100 olarak elde edilmiştir. [1] nolu çalışmada simülasyon modeli ile araç hareketleri ile oluşan ray geriliminin \% 50 oranında azaltıldığı belirtilmiştir. Bu yayında gömülü iletken modeli tercih edilerek ray-toprak potansiyelin azaltılması hedeflenmiştir. [2]'de tasarlanan emulator yardımıyla dokunma gerilimi ve kaçak akımların tahmini yapılmıştır. İki besleme merkezi arası 50 V’a kadar 
DOI: 10.34186/klujes.1051445
Akçay/Kırklareli University Journal of Engineering and Science 7-2 (2021) 272-291

Geliş Tarihi:21.01.2021

çıkan ray gerilimi durumuyla ilgili olarak devresel parametrelerin elde edilmesi anlatılarak gerçekleşen durum yüksek doğrulukla hesaplanmıştır. [3] nolu çalışmada kaçak akım korozyon yayılımının önlenmesi için test ve bakım yöntemlerinin uygulanması ifade edilmiştir. EN 50122 standardının yakalanması için yapılması gereken kaçak akım ölçüm testleri özellikle vurgulanmıştır. [4]'de kaçak akım sistemi için önerilen Base modeli ile kaçak akımların \% 44'e kadar toplandığı belirtilmiştir. [5] nolu çalışmada tristör topraklı sistemin tercih edilmesi durumunda tehlikeli gerilimlerin \% 0.14 seviyesinde gerçekleştiği anlatılmıştır. [6] ile yapılan çalışmada gerçekleştirilen bilgisayar simülasyonu ile ray gerilimi ve kaçak akımlar modellenerek raylar arası çapraz baglama yöntemiyle ray geriliminde \% 20 oranında iyileştirme sağlanmıştır. [7] nolu çalışmada EN 50122 standardı vurgulanarak ray geriliminin azaltılması kategorize edilmiştir. Ray-toprak arası izolasyon direncinin yüksek mertebelerde olması gerektiği belirtilmiştir. [8]'de ise akım izleme bazlı yeni bir yaklaşımla kaçak akım kontrolü sağlanarak $\Delta \mathrm{E}$ hatasında başarı sağlanmıştır. Bu çalışmada ise VLD sisteminin başarısını değerlendirme dışı bırakırsak ray geriliminin iyileştirilmesi için ek cer merkezinin ilavesi ile \% 71.4 iyileştirme başarısı elde edilmiştir. VLD sistemi gözönüne alındığında ise çok yüksek bir başarı sağlandığı ortaya çıkmaktadır. VLD cihazı yüksek performansına ve ray gerilimi konusunda önemli katkıda çözüm sunmasına rağmen sürekli devrede olan ve sürekli güç tüketen bir ekipman olduğu için bazı işletmeler sisteme ilave bir yük getirmeden sistemi kalıcı olarak çözme seçeneklerini değerlendirebilmektedir.

\section{Sonuç}

Bu çalışmada DC beslemeli raylı sistemlerde ray geriliminin kontrol edilerek EN 50122 limitleri içinde kalması için uygulanan yöntemler anlatılmıştır. DC raylı sistem elektrifikasyon sisteminde ortaya çıkan ray gerilimi devre topolojisi üzerinden anlatılarak sonrasında sistemin modellenmesi yapılmıştır. EN 50122 limitlari tablo üzerinden verilerek saniye bazında hangi gerilim aralığının sağlanması gerektiği ifade edilmiştir. VLD cihazının sisteme bağlanması, işletme araç trafiği yönetiminde enerji optimizasyonu, sisteme ek cer merkezinin ilave edilmesi, DC iletim hattı besleme geriliminin değiştirilmesi ve ray iletkenine paralel iletken bağlanması yöntemleri uygulanarak sağlanan başarılar karşılaştırmalı olarak verilmiştir. Yöntemler uygulanırken kullanım 
yaygınlığından dolayı nominal besleme gerilimi olarak $1500 \mathrm{~V}$ DC tercih edilmiştir. İşletme koşulları iki besleme merkezi arasında 4 adet raylı sistem aracının aktif olması durumu benzetilerek ve diğer hat parametreleri girilerek oluşturulmuştur. Besleme gerilimleri olarak EN 50163 ile uyumlu olarak 600 V DC, 750 V DC ve 1500 V DC gerilimleri kullanılmıştır. Ray gerilimi özellikle şehir içi hatlarda olmak üzere sisteme bağlı ekipmanların sağlıklı işletilebilmesi ve sistem emniyet kriterleri bakımından kontrol edilmesi gereken bir unsurdur. Dokunma geriliminin sınırlandırılması için sistem emniyet kriterlerinin en önemli hususlarından biri insan hayatının korunması ve olası iş kazalarının önlenmesi olduğundan dolayı bu durum özellikle takip edilmektedir. Gelişen teknoloji ile birlikte raylı sistem endüstrisinde yaşanan problemlerim çözümü için işletmenin karmaşıklığına en uygun yeni keşifler sisteme entegre edilmektedir. Mevcut klasik yöntemler önemini ve geçerliliğini korumakla birlikte işletmesel verilerden yararlanarak uygulanan yapay zeka, machine learning tabanlı yazılımlarla problemler önceden tespit edilerek çözümler için dinamik bir yanıt sağlayabilmektedir. Bu bilgiler ışığında çalışmada anlatılan yöntemlerin uygulanış biçimleri ve uygulanma zamanları yazılımlarla desteklenerek seçilen yöntemlerin başarısı arttırılabilmektedir.

\section{KAYNAKLAR}

[1] Xu, S.,Y., Li, W., Wang, Y., Q. Effects of Vehicle Running Mode on Rail Potential and Stray Current in DC Mass Transit Systems. Vehicular Technology, IEEE Transactions on. 62, (2013), 3569-3580.

[2] Ibrahem, A., Elrayyah, A., Sozer, Y., Abreu, A. DC Railway System Emulator for Stray Current and Touch Voltage Prediction. IEEE Transactions on Industry Applications. 53(1), 2017, 439-446.

[3] Memon, S. A., Fromme, P. Stray current corrosion mitigation, testing and maintenance in DC transit system. International Journal of Transport Development and Integration. 1(3), (2017), 511519.

[4] Charalambous, C., Cotton, I., Aylott, P., Kokkinos, N. A Holistic Stray Current Assessment of Bored Tunnel Sections of DC Transit Systems. Power Delivery, IEEE Transactions on. 28, (2013), 1048-1056. 
[5] Alamuti, M., M., Nouri, H., Jamali, S., Effects of earthing systems on stray current for corrosion and safety behaviour in practicalmetro systems, IET Electr. Syst. Transp., 1, (2011), 6979.

[6] Tzeng, Y., S., Lee, C.,H. Analysis of Rail Potential and Stray Currents in a Direct-Current Transit System. Power Delivery, IEEE Transactions on. 25, (2010), 1516 - 1525.

[7] Vranesic, K., Serdar, M., Lakusic, S. Analysis of electrical potential and stray currents at DC transit system. International Conference on Sustainable Materials, Systems and Structures (SMSS 2019), 40-44.

[8] Brenna, A., Lazzari, L., Ormellese, M. Stray current control by a new approach based on current monitoring on a potential probe. Corrosion Engineering, Science and Technology. 52(5), (2017), 359-364.

[9] Yang, X.,Hao, X., Zheng, T. Stray Current and Rail Potential Dynamic Simulation System Based on Bidirectional Variable Resistance Module. Diangong Jishu Xuebao/Transactions of China Electrotechnical Society. 34, (2019), 69-81.

[10] Zakowski, K. The determination and identification of stray current source influences on buried pipelines using time/frequency analysis. Anti-corrosion Methods and Materials - Anti-Corros Method Mater. 56, (2009), 330-333.

[11] Du, G., Wang, C., Liu, J., Li, G., Zhang, D. Effect of Over Zone Feeding on Rail Potential and Stray Current in DC Mass Transit System. Mathematical Problems in Engineering. 2, (2016), $1-15$.

[12] Niasati, M., Gholami, A. Overview of stray current control in DC railway systems. International Conference on Railway Engineering, (2008), 1 - 6.

[13] Charalambous, C., Buxton, D., Aylott, P. Practical Contemplation of Stray Current Calculation and Monitoring in DC Mass Transit Systems. IEEE Vehicular Technology Magazine. 11(2), (2016), 24-31.

[14] Susanto, A., Koleva, D., Copuroglu, O., Beek, K., Breugel, K. Mechanical, Electrical and Microstructural Properties of Cement-Based Materials in Conditions of Stray Current Flow. Journal of Advanced Concrete Technology. 11, (2013), 119-134.

[15] Akçay, M., T., Kocaarslan, İ. Simulation of Multi-Vehicle Signaling System with Matlab / Simulink and Design of Train Timetable, Journal of Science and Engineering, 6, (2019), 799-807.

[16] He, J., Yu, L., Wang, X., Song, X. Simulation of transient skin effect of DC railway system based on MATLAB/simulink. Power Delivery, IEEE Transactions on. 28, (2013), 145-152. 
DOI: $10.34186 /$ klujes. 1051445
Akçay/Kırklareli University Journal of Engineering and Science 7-2 (2021) 272-291

Geliş Tarihi:21.01.2021

Kabul Tarihi:30.06.2021

[17] Ogunsola, A., Mariscotti, A., Sandrolini, L. Estimation of Stray Current From a DC-Electrified Railway and Impressed Potential on a Buried Pipe. IEEE Transactions on Power Delivery. 27, (2012), 2238-2246.

[18] Tian, Z., Hillmansen, S., Roberts, C., Weston, P., Chen, L., Zhao, N., Su, S., Xin, T. Modeling and simulation of DC rail traction systems for energy saving. 2014 17th IEEE International Conference on Intelligent Transportation Systems, ITSC. (2014), 2354-2359 